\title{
The Ratio of Diameters Between the Target Artery and the Bypass Modifies Hemodynamic Parameters Related to Intimal Hyperplasia in the Distal End-to-Side Anastomosis
}

\author{
T. GRUS ${ }^{1}$, L. LAMBERT ${ }^{2}$, J. MATĚCHA ${ }^{3}$, G. GRUSOVÁ $^{4}$, M. ŠPAČEK ${ }^{1}$, M. MLČEK ${ }^{5}$ \\ ${ }^{1}$ Department of Cardiovascular Surgery, First Faculty of Medicine, Charles University in Prague, \\ Czech Republic, ${ }^{2}$ Department of Radiology, First Faculty of Medicine, Charles University in \\ Prague, Czech Republic, ${ }^{3}$ Department of Fluid Dynamics and Power Engineering, Faculty of \\ Mechanical Engineering, Czech Technical University in Prague, Czech Republic, ${ }^{4}$ Fourth \\ Department of Internal Medicine, First Faculty of Medicine, Charles University in Prague, Czech \\ Republic, ${ }^{5}$ Department of Physiology, First Faculty of Medicine, Charles University in Prague, \\ Czech Republic
}

Received January 20, 2016

Accepted April 29, 2016

On-line August 19, 2016

\section{Summary}

Hemodynamics in the distal end-to-side anastomosis is related to early development of intimal hyperplasia and bypass failure. In this study we investigated the effect of diameter ratios between the target artery and the bypass at three different angles of the connection. The pulsatile flow field was visualized using particle image velocimetry in transparent models with three different angles of the connection $\left(25^{\circ}, 45^{\circ}, 60^{\circ}\right)$ and the diameter ratio between the bypass and the target artery was $4.6 \mathrm{~mm}: 6 \mathrm{~mm}$, $6 \mathrm{~mm}: 6 \mathrm{~mm}$, and $7.5 \mathrm{~mm}: 6 \mathrm{~mm}$. Six parameters including location and oscillation of the stagnation point, local energy dissipation, wall shear stress (WSS), oscillatory shear index, spatial and temporal gradient of WSS and their distribution in the target artery were calculated from the flow field. In the wider bypass, the stagnation point oscillated in a greater range and was located more proximal to the anastomosis. Energy dissipation was minimal in a wider bypass with a more acute angle. The maximum WSS values were tree times greater in a narrow bypass and concentrated in a smaller circular region at the floor of the anastomosis. The oscillatory shear index increased with wider bypass and more acute angle. The maximum of spatial gradient of WSS concentrated around the floor and toe of the anastomosis and decreased with more acute angle and wider bypass, the temporal gradient of WSS was stretched more towards the side wall. Greater bypass to target vessel ratio and more acute anastomosis angle promote hemodynamics known to reduce formation of intimal hyperplasia.

\section{Key words}

Anastomosis - Peripheral arterial disease - Bypass • Artery • Intimal hyperplasia

\section{Corresponding author}

L. Lambert, Department of Radiology, General University Hospital in Prague, U Nemocnice 2, 12808 Prague 2, Czech Republic. Fax: +420 224963048. E-mail: lambert.lukas@gmail.com

\section{Introduction}

The effectiveness of bypass grafting is determined by its long term patency. Intimal hyperplasia (IH) which is a result of reparative changes after endothelial injury develops early in the first years after the procedure compared to accelerated progression of atherosclerosis, which can occur even later (Grus et al. 2009). Their relative contribution to bypass failure has not been established, but a number of factors contributing to early formation of $\mathrm{IH}$ in the distal anastomosis have been described (Sunamura et al. 2012). Some of these factors can be modified by constructing the distal anastomosis with respect to its hemodynamics (Grus et 
al. 2009). As in most physiological processes, the parameters describing hemodynamics in the anastomosis should be optimized to be close to their ideal values that may even have a protective effect. Wall shear stress, which is the most discussed parameter, causes direct injury to the endothelial wall if it is too high and stimulates local production and release of humoral agents if it is too low (Haruguchi and Teraoka 2003, Sunamura et al. 2007).

The aim of this work was to research hemodynamic parameters involved in the formation of $\mathrm{IH}$ and to propose optimization of flow in the end-to-side anastomosis by manipulating the ratio of diameters between the bypass and the target artery and the anastomosis angle. The researched parameters included 1) the location and oscillation of the stagnation point,
2) local energy dissipation, 3) wall shear stress (WSS), 4) oscillatory shear index (OSI), 5) spatial gradient of WSS (WSSG), and 6) temporal gradient of WSS (WSST).

\section{Methods}

A transparent model of the distal end-to-side anastomosis was created from epoxy resin (Translux D150, Axson technologies, France) by lost-wax casting (Fig. 1). Pulsatile flow simulating natural pulse wave was introduced to the bypass branch and the proximal end of the target artery was closed, which is the most frequent scenario that occurs in $86 \%$ of patients (Grus et al. 2009, Longest et al. 2003).
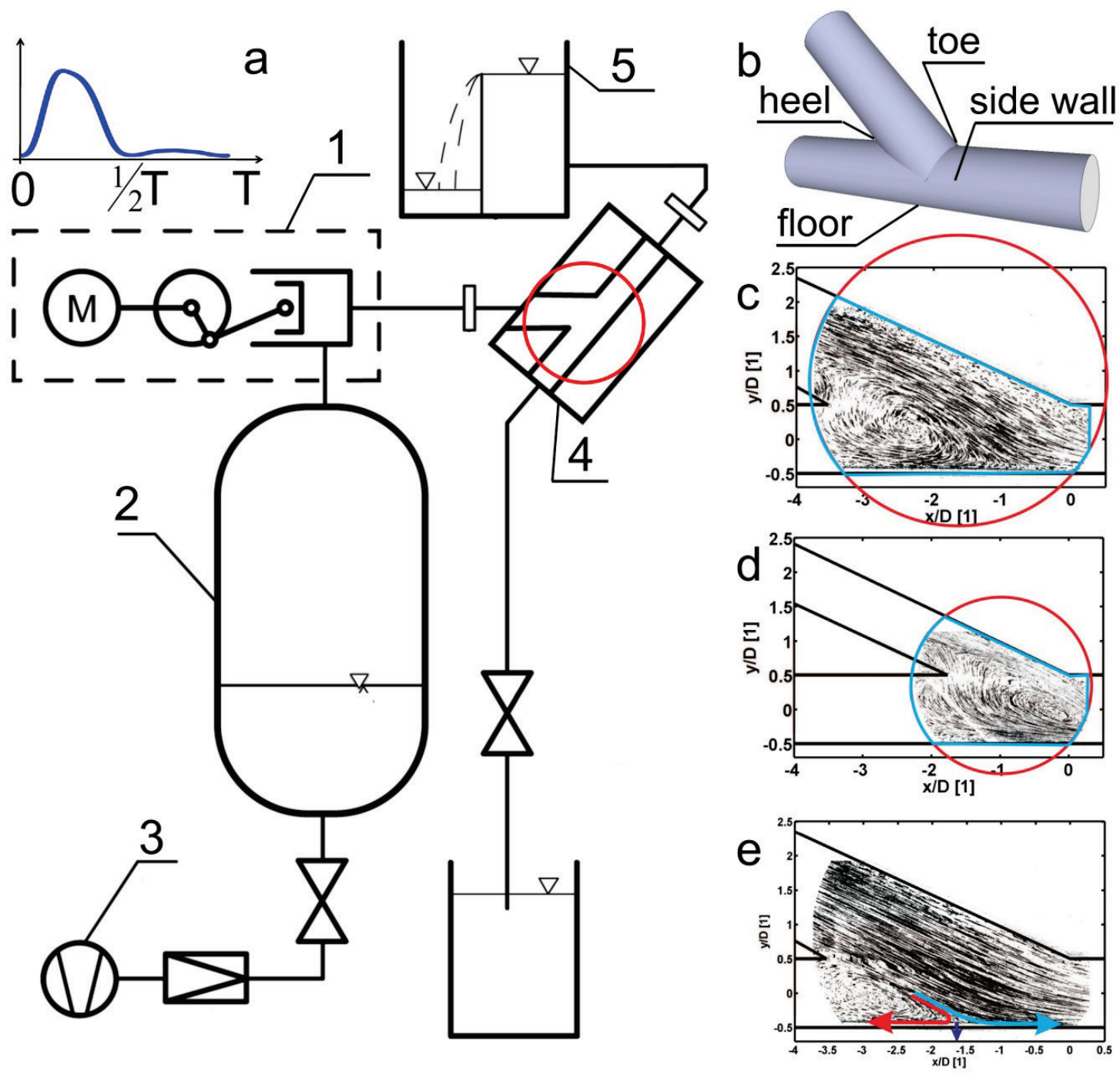

Fig. 1. Schematic drawing of the experimental setup (a) shows pulse generator with stepper motor (1), pressure tank (2) with compressor (3), the bypass model (4), terminal tank with overflow (5), and valves, taps, and sensors (not labeled). The description of regions in the anastomosis is shown in (b). The high-speed camera was recording a circular region (red circle) that is shown in the model (a) and on visualization of the flow using particle image velocimetry in models with different diameter ratios of $P_{M}=1.25$ (c) and $\mathrm{P}_{\mathrm{M}}=0.77$ (d). A stagnation point (e) is a location, where the fluid stagnates (blue arrow) and fluid in the proximal and distal vicinity has opposite flow direction (red and light blue arrows). 
Because in practice each anastomosis is unique, we decided to model nine specific cases: three angles of the anastomosis $\left(25^{\circ}, 45^{\circ}, 60^{\circ}\right)$ and three diameters of the bypass $(4.6 \mathrm{~mm}, 6 \mathrm{~mm}, 7.5 \mathrm{~mm})$. The target vessel had a diameter of $6 \mathrm{~mm}$ resulting in diameter ratios of $\mathrm{P}_{\mathrm{M}}=0.77$ (smaller diameter of the bypass), $\mathrm{P}_{\mathrm{M}}=1.0$ (equal diameters), $\mathrm{P}_{\mathrm{M}}=1.25$ (greater diameter of the bypass). Polyamide particles (diameter $=20 \mu \mathrm{m}$ ) were used as tracers (Grus et al. 2007). We modeled blood kinematic viscosity of $4 \cdot 10^{-6} \mathrm{~m}^{2} \mathrm{~s}^{-1}$ using the similitude theory as described previously (Grus et al. 2007).

Particle image velocimetry (PIV) method was used to visualize the flow with a high resolution speed camera (NanoSense Mk III, Dantec Dynamics, Denmark) and a high speed image amplifier (C9547-03L, Hamamatsu Photonics, Germany) with an effective diameter of $25 \mathrm{~mm}$.

The flow field was computed from serial snapshots using FlowManager (Dantec Dynamics, Denmark) and Matlab (MathWorks, MA, USA). From the flow field, hemodynamic parameters previously reported to influence formation of $\mathrm{IH}$ were obtained:

1) Location and oscillation of the stagnation point, which is a point at the floor of the anastomosis, where the fluid stagnates and flow in its vicinity has opposite direction (Fig. 1) (Haruguchi and Teraoka 2003).

2) Local energy dissipation defined as the difference in kinetic energy of the fluid in the inflow and outflow of the anastomosis (Fillinger et al. 1990).

3) Wall shear stress (WSS) expresses deceleration of blood flow close to the vessel wall, which is a result of tangential frictional force exerted on the intima, and it is expressed as pressure $\left(1 \mathrm{~N} / \mathrm{m}^{2}=1 \mathrm{~Pa}=\right.$ 10 dyne $/ \mathrm{cm}^{2}$ ) (Giddens et al. 1993, Haruguchi and Teraoka 2003).

4) Oscillatory shear index (OSI) quantifies change in the direction and magnitude of WSS (Nordgaard et al. 2010). It is a non-dimensional value that ranges from 0 (purely unidirectional flow) to 0.5 (purely oscillatory flow) (Giddens et al. 1993, He et al. 2013, He and $\mathrm{Ku}$ 1996).

5) Spatial gradient of WSS (WSSG) describes spatial change of WSS in a time point $\left(\mathrm{N} / \mathrm{m}^{3}\right)$ and it may be considered a marker of endothelial cell tension (Lee $e t$ al. 2009, Van Tricht et al. 2006).

6) Temporal gradient of WSS (WSST) describes the rate of change of WSS in a pulse wave cycle at a given location $\left(\mathrm{N} / \mathrm{m}^{2} \cdot \mathrm{s}\right)$ (Ojha 1994).

\section{Results}

\section{Flow visualization}

Flow visualization for $\mathrm{P}_{\mathrm{M}}=1.25$ and $\mathrm{P}_{\mathrm{M}}=0.77$ in an anastomosis with $25^{\circ}$ angle (Fig. 2) in different time points of the pulse wave $(\mathrm{T})$ showed that although during the systolic acceleration (1/4T) the predominant pattern was laminar, there was a small area of vortical flow at the floor of the anastomosis. In the middle of the pulse wave $(2 / 4 \mathrm{~T})$ this area of vortical flow increased in size and extended into the center of the anastomosis shifting the area of laminar flow towards the toe of the anastomosis. This effect was much more prominent with a narrower bypass $\left(\mathrm{P}_{\mathrm{M}}=0.77\right)$ where laminar flow almost disappeared.

\section{Location and shift of the stagnation point}

The stagnation point located at the floor of the anastomosis was apparent between $15 \%$ and $50 \%$ of the pulse cycle in which period it also changed its location (Figs 2 and 3). In the wider bypass $\left(\mathrm{P}_{\mathrm{M}}=1.25\right)$ the stagnation point moved in a greater range and it was located more proximal to the anastomosis. The same applied to the angle of the anastomosis (Fig. 3b).

\section{Energy dissipation}

Energy dissipation during the pulse wave cycle was minimal with acute anastomosis angle and greater diameter of the bypass (Fig. 3).

\section{Wall shear stress}

In the model with narrow bypass $\left(\mathrm{P}_{\mathrm{M}}=0.77\right)$, the maximum WSS values were three times greater than in wide bypass $\left(\mathrm{P}_{\mathrm{M}}=1.25\right)$ and concentrated in a smaller circular region at the floor of the anastomosis (Fig. 4). These differences were more pronounced if the anastomosis angle was greater $\left(45^{\circ}\right.$ and $60^{\circ}$ compared to $25^{\circ}$ ).

\section{Oscillatory shear index}

The values of OSI increased with more acute anastomosis angle and greater bypass to target vessel diameter ratios (Fig. 4).

\section{Spatial WSS gradient}

Maximal values of WSSG occurred at the floor and the toe of the anastomosis and decreased with more acute angles and greater bypass to target vessel diameter ratio (Fig. 4). 


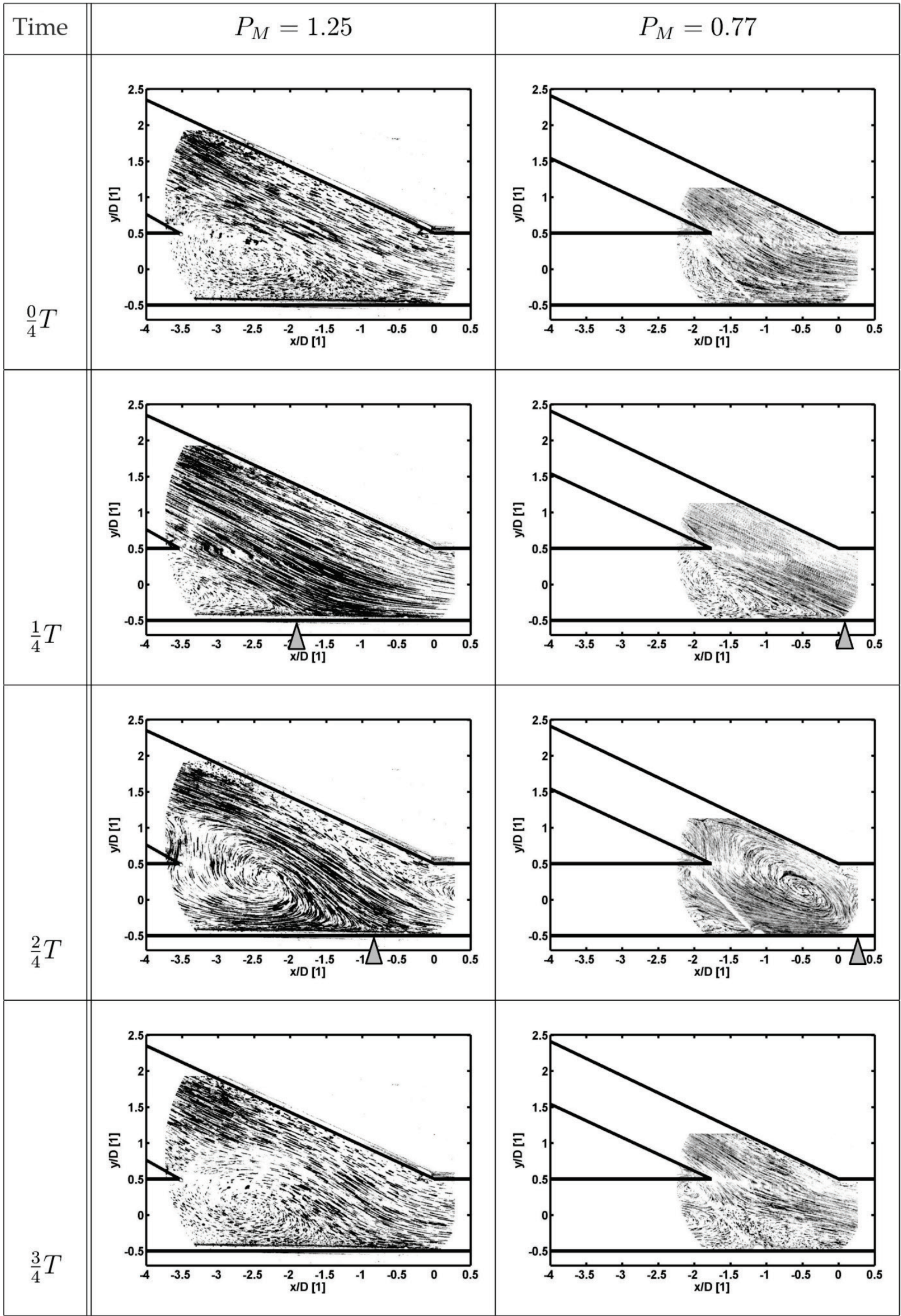

Fig. 2. Flow visualization for $P_{M}=1.25$ and $P_{M}=0.77$ in an anastomosis with $25^{\circ}$ angle at different time points of the pulse wave with a period denoted by $\mathrm{T}$. Arrowheads mark the stagnation point which is well defined in $1 / 4 \mathrm{~T}$ and $2 / 4 \mathrm{~T}$. 
Location of the stagnation point Shift of the stagnation point
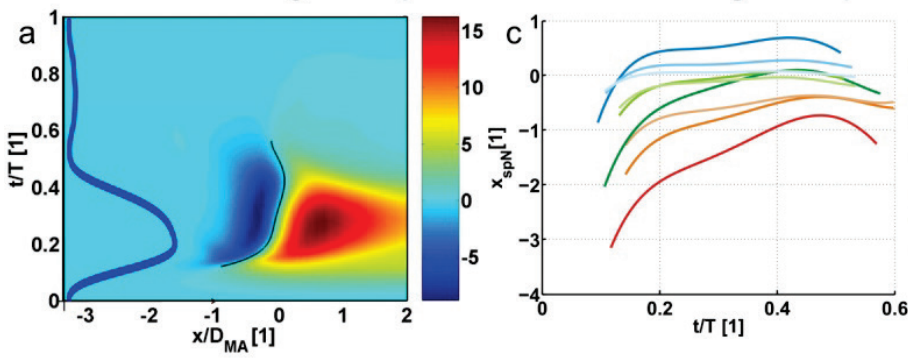

b

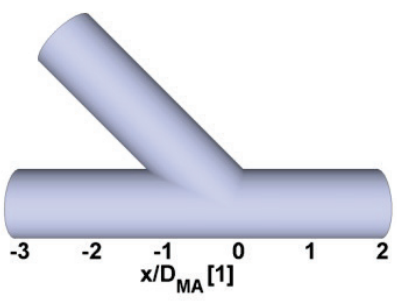

Local energy dissipation

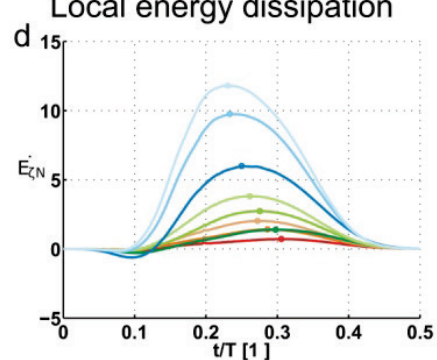

$-P=1.25, \alpha=25^{\circ}$

$-P=1.25, \alpha=45^{\circ}$

$-P=1.25, \alpha=60^{\circ}$

$-P=1.00, \alpha=25$

$P=1.00, \alpha=45^{\circ}$

- $P=1.00, \alpha=60$

$-P=0.77, \alpha=25$

$P=0.77, \alpha=45^{\circ}$

$P=0.77, \alpha=60^{\circ}$

Fig. 3. Location of the stagnation point in a $45^{\circ}$ anastomosis with equal diameters of the bypass and the target vessel (black curve) as the boundary between areas of positive (red color) and negative (blue color) wall shear stress changes during the pulse wave cycle $(\mathbf{a}, \mathbf{b})$. In an anastomosis with wider bypass ( $P_{M}=$ ratio of diameters between the bypass and the target vessel) and more acute angle (a), the stagnation point oscillates in a greater range and it is located more proximal to the anastomosis (c). Energy dissipation $E_{\overparen{N} N}$ is minimal with an acute anastomosis angle and wide bypass (d).

Map of maximal wall shear stress projected on side wall of the target vessel

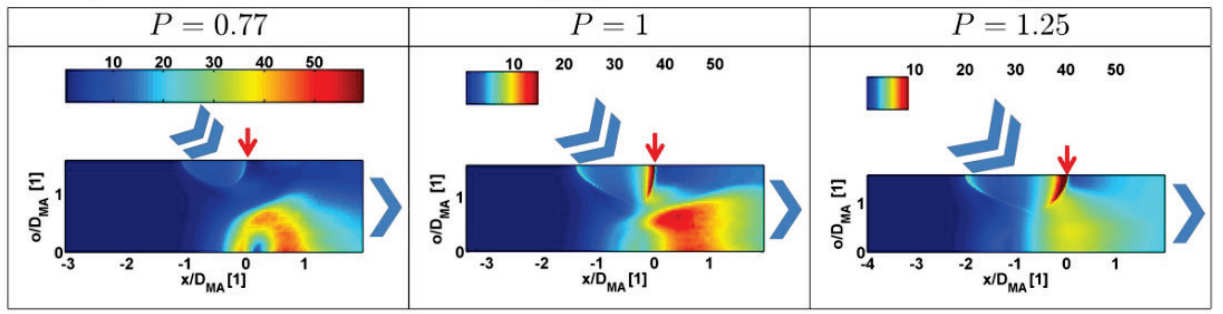

Map of oscilatory shear index

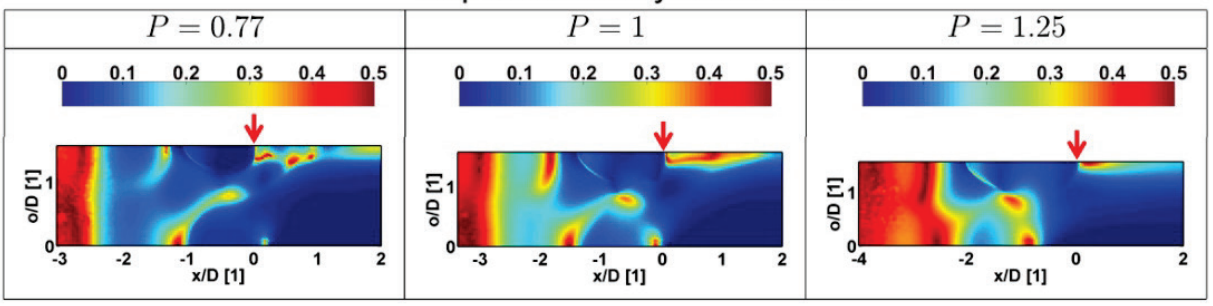

Map of maximal wall shear stress spatial gradient

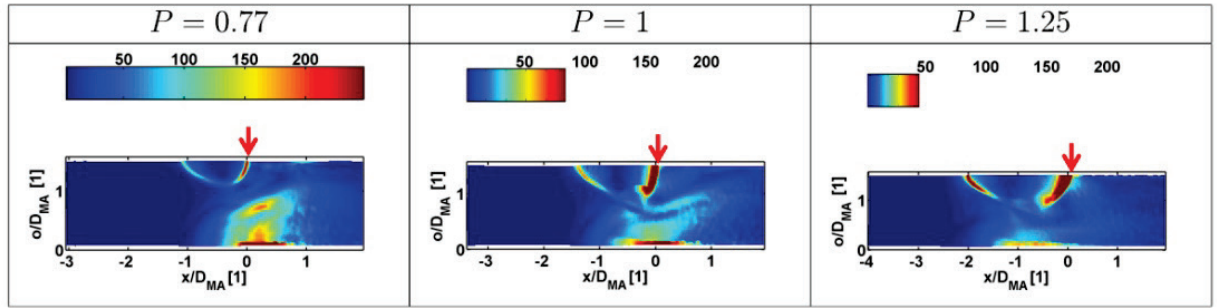

Map of maximal wall shear stress temporal gradient

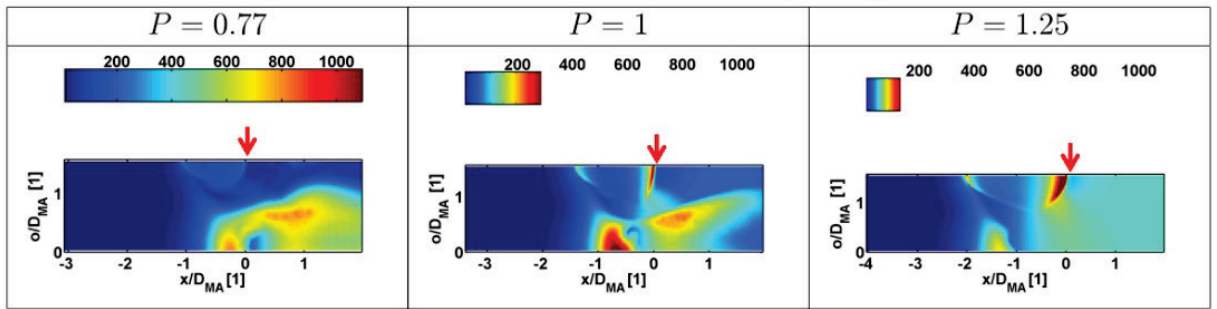

Fig. 4. Map of maximal wall shear stress (WSS), oscillatory shear index (OSI), wall shear stress spatial gradient (WSSG), and wall shear stress temporal gradient (WSST) projected on the side wall of the target vessel in a $45^{\circ}$ distal end-to-side anastomosis with three different bypass to target vessel diameter ratios. Red arrow marks the toe of the anastomosis, chevrons indicate flow direction. Note that color scale ranges vary among images. 
Table 1. Influence of bypass to target artery diameter ratios and the anastomosis angle on parameters describing hemodynamics in the end-to-side anastomosis.

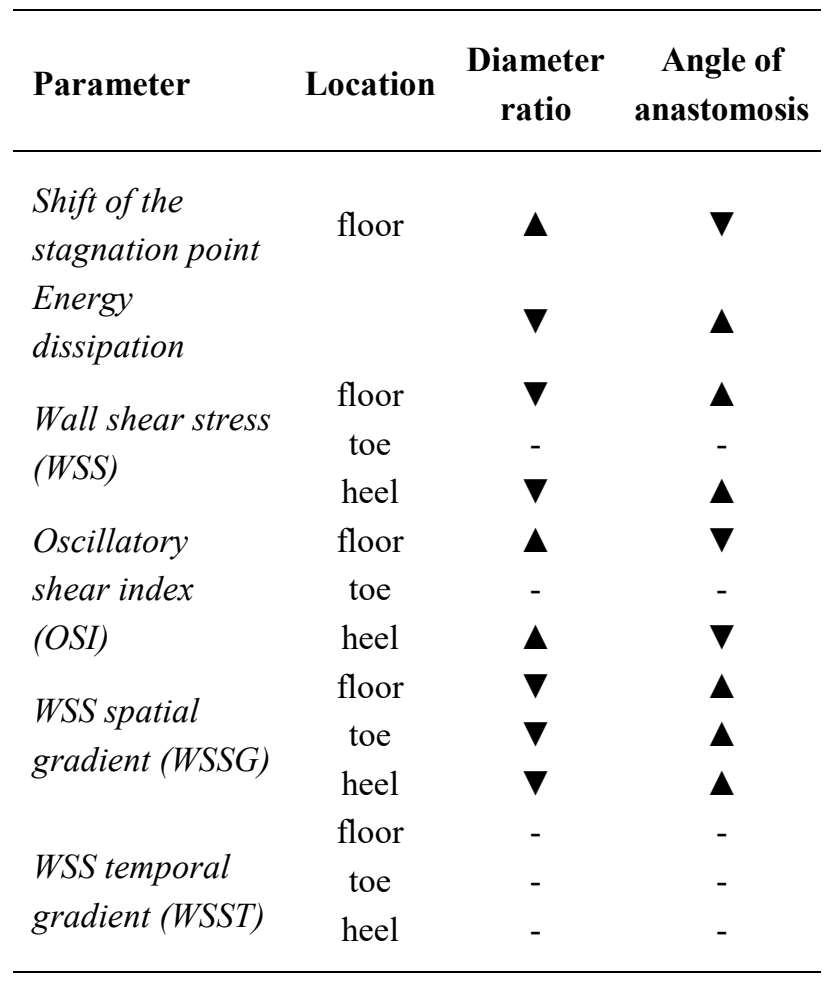

$\Delta$, increases with the parameter in the column heading; $\boldsymbol{\nabla}$, decreases with the parameter; -, does not change substantially with the parameter.

\section{Temporal WSS gradient}

WSST followed the same trend as WSSG but its maxima extended more towards the side wall (Fig. 4).

The influence of the diameter ratios and the angle of the anastomosis on the measured or calculated hemodynamic parameters is summarized in Table 1.

\section{Discussion}

About $20 \%$ of infrainguinal bypass reconstructions lose their primary patency within the first year after the operation depending of the type of graft used (Klinkert et al. 2004). Early stenosis is commonly caused by a technical error or formation of $\mathrm{IH}$, but after one year, accelerated atherosclerosis becomes the leading cause (Hui 2008, Subbotin 2007). Proliferation of the intima is a physiological response to endothelial injury, which is most often mechanical during angioplasty but sometimes also caused by turbulent blood flow. Injured endothelial cells release mediators and growth factors such as FGF, PDGF, TNF- $\alpha$ that stimulate migration of smooth muscle cells into the intima and synthesis of extracellular matrix resulting in tough narrowing of the lumen (Cunningham and Gotlieb 2004). This process is also stimulated by stagnation of blood and low WSS by signaling from membrane epitopes on the endothelial cells such as glycocalyx and release of signal molecules such as TGF- $\beta$, PDGF (Haruguchi and Teraoka 2003, Newby and Zaltsman 2000, Shi and Tarbell 2011).

Stagnation of blood is damaging, wherever it occurs. But if it changes location periodically, its adverse effects are dispersed on a larger area and therefore mitigated. This is expressed as the shift of the stagnation point which was maximal with the $25^{\circ}$ angle and greater diameter of the bypass. At the same time, the stagnation point was located more towards the proximal end of the target vessel and therefore influencing less the part of the lumen, where laminar flow from the bypass into the outflow part of the target vessel occurs. Simultaneously, the WSS decreased towards physiological values and its maximal values were spread over a larger area. Too low values of WSS below $5 \mathrm{dyne} / \mathrm{cm}^{2}$ trigger proliferation of extracellular matrix and formation of intimal hyperplasia while to high values above 70 dyne $/ \mathrm{cm}^{2}$ cause direct mechanical injury to the endothelial cells and their epitopes (Leon and Greisler 2003). In order to maintain adequate hemodynamics, the diameter of an artery adapts to achieve WSS values around 15 dyne $/ \mathrm{cm}^{2}$ (Giddens et al. 1993). The spatial and temporal gradients of WSS were most prominent at the toe of the anastomosis which explains formation of $\mathrm{IH}$ at that site (Ojha 1994).

Energy dissipation is one of the less frequently discussed parameters. It is closely related to other hemodynamic parameters and therefore to the development of $\mathrm{IH}$ as well (Fillinger et al. 1990). Although it does not affect the anastomosis directly, the drop in kinetic energy of blood also influences the flow distally from the stenosis and may promote clot formation and accelerate atherosclerosis in the outflow bed.

The visualization of the presented hemodynamic parameters is in accordance with current knowledge that IH occurs at the floor, heel, and less commonly the toe of the end-to-side anastomosis and it is less common in reconstructions with more acute angles (Grus et al. 2009). The benefit of a bypass to target artery diameter ratio greater than one has also been proved in clinical practice.

The distal end-to-side anastomosis of a bypass to a target vessel is usually constructed roughly in a $45^{\circ}$ angle. Therefore the arteriotomy has to be 1.6 to 1.8 times longer than the diameter of the bypass, which is slightly 
greater $(6-8 \mathrm{~mm})$ than the diameter of the popliteal artery (4-6 mm) (Longest et al. 2003). Although a more acute angle would contribute to better hemodynamics in the anastomosis, it requires longer arteriotomy and more space because the anastomosis is longer (Grus et al. 2009). Fortunately, mild tension from the bypass results in straightening of the outflow part of the target artery thus further reducing the angle.

A distal femoropopliteal bypass can be placed along the medial condyle of the femur or embedded dorsally along the popliteal vascular bundle. The choice of its placement determines to great extent the angle of the distal anastomosis and the former technique invariably results in greater angles (Grus et al. 2016). Unfortunately, constructing an end-to-end bypass that would not suffer from the detrimental effects of adverse WSS values is not an option. This procedure would require ligation of the proximal part of the target vessel with damage to the collateral flow that is usually present in patients with peripheral artery disease. It does not improve patency and failure of the bypass results in limb amputation more often compared to end-to-side anastomosis (Schouten et al. 2005).

Recognition of parameters of the anastomosis geometry that lead to detrimental flow and formation of IH are fundamental to its optimization including adaptation of the margins of the incision in the target vessel, the suture, and the shape of the bypass with various degrees of conicity, cuffs and patches (Fan et al. 2008, Giordana et al. 2005, Longest et al. 2003, Walsh et al. 2003).

There are several limitations of this study. Firstly, it was performed in a rigid model and therefore it did not address pulsatility of the wall, compliance mismatch between the bypass and the target vessel
(Ballyk et al. 1997), interactions between blood and the endothelium including surface tension. Secondly, there is a subgroup of patients who have some inflow to the target artery preserved by either collateral flow or incomplete occlusion. Thirdly, rheological properties of blood under different conditions have not been modeled. However, they have only small influence on the flow through the anastomosis (Wang et al. 2008). Fourthly, there are other factors influencing flow beyond the anastomosis including the outflow bed and peripheral arterial resistance, type and length of the prosthesis, and flow change under exercise that are beyond the scope of this study. Lastly, hemodynamics is one of the factors known to influence the formation of IH. Interaction of platelets, endothelial and smooth muscle cells, erythrocytes, white blood cells, cytokines and growth factors has been previously described as well (Liu et al. 1989, Subbotin 2007).

In conclusion, findings of this in vitro study explain why a more acute angle of the anastomosis and greater ratio between the diameter of the bypass and the target artery contribute to a more favorable flow with improvement of hemodynamic parameters such as WSS, OSI, oscillation of the stagnation point, WSSG, and WSST in a direction that is known to reduce formation of intimal hyperplasia. An in vivo study would be needed to confirm these observations.

\section{Conflict of Interest}

There is no conflict of interest.

\section{Acknowledgements}

This article was supported by the following grant: 15-27941A.

\section{References}

BALLYK PD, WALSH C, BUTANY J, OJHA M: Compliance mismatch may promote graft-artery intimal hyperplasia by altering suture-line stresses. J Biomech 31: 229-237, 1997.

CUNNINGHAM KS, GOTLIEB AI: The role of shear stress in the pathogenesis of atherosclerosis. Lab Invest 85: 9-23, 2004.

FAN Y, XU Z, JIANG W, DENG X, WANG K, SUN A: An S-type bypass can improve the hemodynamics in the bypassed arteries and suppress intimal hyperplasia along the host artery floor. J Biomech 41: 2498-2505, 2008.

FILLINGER MF, KERNS DB, BRUCH D, REINITZ ER, SCHWARTZ RA: Does the end-to-end venous anastomosis offer a functional advantage over the end-to-side venous anastomosis in high-output arteriovenous grafts? J Vasc Surg 12: 676-690, 1990.

GIDDENS DP, ZARINS CK, GLAGOV S: The role of fluid mechanics in the localization and detection of atherosclerosis. J Biomech Eng 115: 588-594, 1993. 
GIORDANA S, SHERWIN SJ, PEIRÓ J, DOORLY DJ, CRANE JS, LEE KE, CHESHIRE NJW, CARO CG: Local and global geometric influence on steady flow in distal anastomoses of peripheral bypass grafts. $J$ Biomech Eng 127: 1087-1098, 2005.

GRUS T, LINDNER J, VIK K, TOSOVSKÝ J, MATECHA J, NETREBSKÁ H, TŮMA J, ADAMEC J: Particle image velocimetry measurement in the model of vascular anastomosis. Prague Med Rep 108: 75-86, 2007.

GRUS T, LINDNER J, VIDIM T, TOSOVSKY J, MATECHA J, ROHN V, LAMBERT L, GRUSOVA G: The anastomosis angle is a key to improved long-term patency of proximal femoropopliteal bypass. Ann Vasc Surg 23: 598-605, 2009.

GRUS T, LAMBERT L, BANERJEE R, GRUSOVA G, ROHN V, VIDIM T, MITAS P: Intercondylar route of prosthetic infragenicular femoropopliteal bypass has better primary, assisted, and secondary patency but not limb salvage rate compared to the medial route. Biomed Res Int 2016: 1256414, 2016.

HARUGUCHI H, TERAOKA S: Intimal hyperplasia and hemodynamic factors in arterial bypass and arteriovenous grafts: a review. J Artif Organs 6: 227-235, 2003.

HE X, KU DN: Pulsatile flow in the human left coronary artery bifurcation: average conditions. J Biomech Eng 118: 74-82, 1996.

HE Y, TERRY CM, NGUYEN C, BERCELI SA, SHIU Y-TE, CHEUNG AK: Serial analysis of lumen geometry and hemodynamics in human arteriovenous fistula for hemodialysis using magnetic resonance imaging and computational fluid dynamics. J Biomech 46: 165-169, 2013.

HUI DY: Intimal hyperplasia in murine models. Curr Drug Targets 9: 251-260, 2008.

KLINKERT P, POST PN, BRESLAU PJ, VAN BOCKEL JH: Saphenous vein versus PTFE for above-knee femoropopliteal bypass. A review of the literature. Eur J Vasc Endovasc Surg 27: 357-362, 2004.

LEE S-W, ANTIGA L, STEINMAN DA: Correlations among indicators of disturbed flow at the normal carotid bifurcation. J Biomech Eng 131: 061013, 2009.

LEON L, GREISLER HP: Vascular grafts. Expert Rev Cardiovasc Ther 1: 581-594, 2003.

LIU MW, ROUBIN GS, KING SB: Restenosis after coronary angioplasty. Potential biologic determinants and role of intimal hyperplasia. Circulation 79: 1374-1387, 1989.

LONGEST PW, KLEINSTREUER C, ARCHIE JP: Particle hemodynamics analysis of Miller cuff arterial anastomosis. J Vasc Surg 38: 1353-1362, 2003.

NEWBY AC, ZALTSMAN AB: Molecular mechanisms in intimal hyperplasia. J Pathol 190: 300-309, 2000.

NORDGAARD H, SWILLENS A, NORDHAUG D, KIRKEBY-GARSTAD I, LOO DV, VITALE N, SEGERS P, HAAVERSTAD R, LOVSTAKKEN L: Impact of competitive flow on wall shear stress in coronary surgery: computational fluid dynamics of a LIMA-LAD model. Cardiovasc Res 88: 512-519, 2010.

OJHA M: Wall shear stress temporal gradient and anastomotic intimal hyperplasia. Circ Res 74: 1227-1231, 1994.

SCHOUTEN O, HOEDT MTC, WITTENS CHA, HOP WCJ, VAN SAMBEEK MRHM, VAN URK H; VASCAN STUDY GROUP: End-to-end versus end-to-side distal anastomosis in femoropopliteal bypasses; results of a randomized multicenter trial. Eur J Vasc Endovasc Surg 29: 457-462, 2005.

SHI Z-D, TARBELL JM: Fluid flow mechanotransduction in vascular smooth muscle cells and fibroblasts. Ann Biomed Eng 39: 1608-1619, 2011.

SUBBOTIN VM: Analysis of arterial intimal hyperplasia: review and hypothesis. Theor Biol Med Model 4: 1-20, 2007.

SUNAMURA M, ISHIBASHI H, KARINO T: Flow patterns and preferred sites of intimal thickening in diametermismatched vein graft interpositions. Surgery 141: 764-776, 2007.

SUNAMURA M, ISHIBASHI H, KARINO T: Flow patterns and preferred sites of intimal thickening in bypass-grafted arteries. Int Angiol J 31: 187-197, 2012.

VAN TRICHT I, DE WACHTER D, TORDOIR J, VERDONCK P: Comparison of the hemodynamics in $6 \mathrm{~mm}$ and 4-7 mm hemodialysis grafts by means of CFD. J Biomech 39: 226-236, 2006.

WALSH MT, KAVANAGH EG, O'BRIEN T, GRACE PA, MCGLOUGHLIN T: On the existence of an optimum endto-side junctional geometry in peripheral bypass surgery - a computer generated study. Eur J Vasc Endovasc Surg 26: 649-656, 2003.

WANG Q-Q, PING B-H, XU Q-B, WANG W: Rheological effects of blood in a nonplanar distal end-to-side anastomosis. J Biomech Eng 130: 051009, 2008. 